\title{
ORIGINAL ARTICLE Inbreeding interferes with the heat-shock response
}

\author{
Kristin Franke and Klaus Fischer \\ Inbreeding is typically detrimental to individual fitness, with negative effects being often exaggerated in stressful environments. \\ However, the causal mechanisms underlying inbreeding depression in general and the often increased susceptibility to stress in \\ particular are not well understood. We here test whether inbreeding interferes with the heat-shock response, comprising an \\ important component of the stress response which may therefore underscore sensitivity to stress. To this end we subjected the \\ tropical butterfly Bicyclus anynana to a full-factorial design with three temperatures and three levels of inbreeding, and \\ measured the expression of heat-shock protein (HSP) 70 via qPCR. HSP70 expression increased after exposure to heat as \\ compared with cold or control conditions. Most strikingly, inbreeding strongly interfered with the heat-shock response, with \\ inbred individuals showing a very weak upregulation of HSP7O only. Our results thus indicate that, in our study organism, \\ interference with the heat-shock response may be one mechanism underlying reduced fitness of inbred individuals, especially \\ when exposed to stressful conditions. However, these indications need to be corroborated using a broader range of different \\ temperatures, genes and taxa. \\ Heredity (2015) 114, 80-84; doi:10.1038/hdy.2014.72; published online 30 July 2014
}

\section{INTRODUCTION}

In modern human-transformed landscapes, the populations of many species are under various pressures including habitat loss and degradation, resulting in increasingly small and isolated populations (Mikkelsen et al., 2010). Small population size, in turn, increases the risk of genetic erosion through drift and inbreeding (Hoffmann and Hercus, 2000). While the effects of reduced genetic variation for population survival are not always obvious and thus a matter of debate, a wealth of studies has reported negative effects of inbreeding on fitness-related traits (Armbruster and Reed, 2005; Fox and Reed, 2011). Inbreeding reduces for instance fecundity, egg hatching success and body mass, and may increase susceptibility to stressful or changing environmental conditions (Fox and Reed, 2011).

In nature, environmental stress is often caused by extreme temperatures (David et al., 1998). Temperature generally is an important environmental factor affecting various traits such as foraging activity, migration, growth, metabolism or survival (Atkinson, 2008). To buffer detrimental effects of temperature stress organisms have evolved several mechanisms, among which the heatshock response appears to be a particularly important one (Lindquist, 1986). Heat-shock proteins (HSPs) are highly conserved among organisms and are activated under stressful conditions such as heat, cold or chemical stress (Sørensen et al., 2003; Koštál and TollarováBorovanská, 2009). Out of the six families of HSPs, the HSP70 family is the most frequently investigated one (for example, Kristensen et al., 2003; Koštál and Tollarová-Borovanská, 2009). The inducible HSP70 works like a chaperone and assists in protein (re-)folding, alignment and synthesis (Sørensen et al., 2003).

Inbreeding depression is often more pronounced under stressful than under benign environmental conditions (Armbruster and Reed, 2005; Fox and Reed, 2011). However, the mechanisms underlying such increased sensitivity to environmental (including temperature) stress and inbreeding depression in general are not well understood (for example, Vermeulen and Bijlsma, 2004; Kristensen et al., 2005). Based on its crucial importance for cell functioning and the ability to deal with an array of stressors (Sørensen et al., 2003), the heat-shock response could principally represent such a mechanism. Thus, if inbreeding would negatively affect the heat-shock response, this could well underlie detrimental effects on individual performance and increased sensitivity to stress.

Against this background, we here investigate the effects of inbreeding and temperature on HSP70 expression in the tropical butterfly Bicyclus anynana. This species shows substantial inbreeding depression even at relatively mild levels of inbreeding, resulting in reduced egg hatching success, pupal and thorax mass and fat content (Dierks et al., 2012; Franke and Fischer, 2013). Note in this context that tropical species may be, in general, more strongly affected by inbreeding than more widespread species (Bechsgaard et al., 2013). Furthermore, temperature stress resistance responds readily to environmental manipulations in this species (Fischer et al., 2010; Franke and Fischer, 2013). We specifically test the hypothesis that inbreeding interferes with the heat-shock response. To quantify HSP70 expression we used quantitative real-time reverse transcription PCR (qPCR; Huggett et al., 2005), investigating expression levels relative to a reference group (Livak and Schmittgen, 2001).

\section{MATERIAL AND METHODS}

\section{Study organism}

Bicyclus anynana (Butler, 1897; Nymphalidae, Satyrinae) is a tropical fruitfeeding butterfly, ranging from southern Africa to Ethiopia (Larsen, 1991). The species inhabits regions with alternating dry and wet seasons and shows accordingly two seasonal morphs. During the colder dry season $\left(\sim 18^{\circ} \mathrm{C}\right.$, May 
until November) the species has rather uniform wing patterns and small eyespots, whereas it exhibits large eyespots and bright bands on both wings in the warmer wet season $\left(\sim 23^{\circ} \mathrm{C}\right.$, December until April; Lyytinen et al., 2004). During the dry season, reproduction ceases and butterflies do not mate before the onset of the next wet season (Brakefield and Kesbeke, 1997). A stock population of B. anynana was founded at Greifswald University in 2007 from several hundred individuals derived from a well-established stock population at Leiden University, The Netherlands. The latter was founded in 1988 from over 80 gravid females collected at a single locality in Nkhata Bay, Malawi. To maintain high levels of heterozygosity, several hundred adults are reared in each generation (Van't Hof et al., 2005). For this experiment animals from the Greifswald stock population were used.

\section{Experimental design}

To investigate effects of inbreeding and temperature on the expression of heatshock protein (HSP70), three inbreeding levels were established by means of full-sib matings: inbreeding level 2 resulting from two full-sib matings in consecutive generations ('I2'; $\mathrm{F}=0.38$ ), inbreeding level 1 resulting from one full-sib mating ('Il'; $\mathrm{F}=0.25$ ) and outbred controls resulting from random mating ('C'; $\mathrm{F}=0$ ). Expected inbreeding coefficients $(\mathrm{F})$ were calculated assuming that the stock population has an inbreeding level of zero (Kristensen et al., 2003). The different inbreeding levels were set up from the stock population as follows. First, 80 virgin females and males each were randomly selected from the stock population and set up in a cylindrical hanging cage $(30 \times 39 \mathrm{~cm})$ for mating. The first 50 pairs to mate were isolated and placed individually in translucent 1-litre plastic containers. After mating, males were removed from the containers, while females were provided with a leaf of maize for egg-laying and with moist banana for adult feeding. The eggs produced by individual females were afterwards transferred to elongated, sleeve-like gauze cages containing a young maize plant for further development. Consequently, each 'sleeve' cage represented one full-sib family.

The butterflies resulting from the above families were used to set up the 'I2' treatment by mating one virgin brother to one virgin sister per full-sib family (1st full-sib mating). We performed two such full-sib matings per family to ensure a sufficiently high number of inbred families, but one replicate per family was discarded after having tested for hatching success. Following the first full-sib mating, the above procedure was repeated once (2nd full-sib mating). Parallel to the second generation of the ' $\mathrm{I} 2$ ' treatment, the 'I1' treatment was set up as described above by mating random virgin males and females and rearing full-sib families in 'sleeve' cages. Thereafter, the control treatment was set up by mating random, virgin stock individuals. This staggered design resulted in 33 ' $\mathrm{C}$ ' families, 36 ' $\mathrm{I1}$ ' families and 46 ' $\mathrm{I} 2$ ' families, which were available for testing simultaneously. Per family, 40 larvae were reared in the aforementioned 'sleeve' cages, being fed with young maize plants ad libitum. Resulting pupae were collected daily and weighed on day 1 after pupation to the nearest $0.1 \mathrm{mg}$ (balance: KERN 410). Afterwards, pupae were kept individually in translucent plastic cups (volume $125 \mathrm{ml}$ ) covered with gauze. Upon adult eclosion, pupal development time and sex were scored.

On the day following adult eclosion, butterflies were randomly divided among three treatment groups being exposed for $2 \mathrm{~h}$ to ${ }^{\circ} \mathrm{C}$ (cold stress), $27^{\circ} \mathrm{C}$ (control) or $39^{\circ} \mathrm{C}$ (heat stress). The control temperature used here reflects the average daily highs during the favourable wet season in the butterfly's natural habitat and is known to be very beneficial to development and reproduction (Brakefield and Kesbeke, 1997). The cold and the high temperature used were selected to induce severe stress, which is typically needed to upregulate heatshock protein expression (Feder and Hofmann, 1999). The high temperature of $39^{\circ} \mathrm{C}$ certainly involves substantial stress and cannot be survived in the

Table 1 Primer sequences for the target gene heat-shock protein (HSP) 70 and the selected housekeeping gene Actin A1

\begin{tabular}{lll} 
Gene & Forward primer $\left(5^{\prime}-3^{\prime}\right)$ & Reverse primer $\left(5^{\prime}-3^{\prime}\right)$ \\
\hline HSP 70 & AGAGAACAGCACCGGAAGAA & CGCTTGTTTGACGCTGAATA \\
Actin A1 & GAGAGGGAAATCGTTCGTGACATC & AGGAAGGAAGGCTGGAAGAGAG
\end{tabular}

longer term (own results). However, it is likely that such high temperatures regularly occur in the butterfly's natural environment, whereas $1{ }^{\circ} \mathrm{C}$ is probably not encountered in nature. Butterflies were frozen immediately after temperature exposure in liquid nitrogen and stored at $-80^{\circ} \mathrm{C}$ for later analyses. Rearing and maintenance took place in a single climate room under conditions mimicking the wet season (that is, at $27^{\circ} \mathrm{C}, 70 \pm 5 \%$ relative humidity, and a photoperiod of L12:D12). Butterflies were fed with moist banana throughout.

\section{Quantification of HSP expression}

The expression of HSP70 was measured by quantitative real-time reverse transcription polymerase chain reaction ( $\mathrm{qPCR})$. First, legs, wings and head were removed from each butterfly and abdomen and thorax were separated. Between 9.8 and $19.8 \mathrm{mg}$, thorax tissue was used for RNA isolation using the innuPREP RNA Mini Kit (Analytik Jena AG, Jena, Germany) according to the manufacturer's instructions. Total RNA was quantified with a Nano Drop spectrophotometer (peqlab, ND-1000). The $\mathrm{OD}_{260} / \mathrm{OD}_{280}$ ratio (that is, the ratio of the optical densities measured at 260 and $280 \mathrm{~nm}$, respectively) ranged between 2.06 and 2.33. The total RNA was diluted to $250 \mathrm{ng}^{-1}$, and $4 \mu \mathrm{l}$ of the diluted RNA was used for the conversion into cDNA. For cDNA conversion, the RevertAid First Strand cDNA Synthesis Kit and an oligo $(\mathrm{dt})_{12-18}$ primer (Thermo Scientific, Waltham, MA, USA) was used following the manufacturer's instructions.

qPCR was carried out using the Sensi FAST SYBR Lo-Rox Kit (Bioline, London, UK). To establish primers for HSP70, we blasted known HSP70 sequences from several species against the available sequences of $B$. anynana in the NCBI database (http://www.ncbi.nlm.nih.gov/). Afterwards we created different backward and reverse primer pairs with the program Primer 3 (http:// bioinfo.ut.ee/primer3-0.4.0/) for testing. The best results were achieved when using the HSP70 sequence of the firebug Pyrrhocoris apterus (http:// www.ncbi.nlm.nih.gov, FJ386397.1). In qPCR analyses it is important to normalize the expression of the target gene by using a reference gene to avoid false interpretations based on experimental artefacts (Ullmannová and Haškovec, 2003; Huggett et al., 2005). Such reference genes, being used as internal standard, are typically housekeeping genes and should exhibit constant levels of expression across treatment groups (Ullmannová and Haškovec, 2003; Huggett et al., 2005). Here we used the housekeeping gene Actin Al as reference gene. Primers for Actin Al were derived from Teng et al. (2012); see Table 1 for the primers used.

Two master mixes (for HSP70 and Actin A1) were used for qPCR analyses. Per mix, we used $10 \mu \mathrm{l}$ of the Sensi FAST SYBR Lo-Rox Kit (Bioline), $0.5 \mu \mathrm{l}$ each of the respective forward and reverse primer $\left(100 \mathrm{pmol}^{-1} \mathrm{l}^{-1}\right)$, and $8 \mu \mathrm{l}$ aqua dest. per well of a 96-well plate (Frame Star Fast Plate 96, 4titude, Surrey, UK); we used $19 \mu \mathrm{l}$ master mix and $1 \mu \mathrm{l}$ cDNA. We ran two replicates for HSP70 and Actin A1 expression each per individual. Consequently, 21 animals were measured per plate together with 12 non-template controls. These controls contained RNAse free water instead of cDNA. Plates were sealed (q-stick adhesive for qPCR, 4titude) and afterwards centrifuged for a few seconds to make sure that all liquid is inside the well (MPS 1000, Labnet, Edison, NJ, USA). Then, plates were incubated at $95^{\circ} \mathrm{C}$ for $2 \mathrm{~min}$ and subsequently run on an Applied Biosystems 7500 Real-Time PCR System (Life Technologies, Carlsbad, CA, USA), using 45 cycles of $5 \mathrm{~s}$ at $95^{\circ} \mathrm{C}$ and of $30 \mathrm{~s}$ at $60^{\circ} \mathrm{C}$ each.

\section{Statistical analyses}

We calculated the relative quantification (RQ) of HSP70 as follows:

$$
\begin{aligned}
& \Delta \mathrm{C}_{\mathrm{T} \text { Sample }}=\mathrm{C}_{\mathrm{T} \text { SampleHSP }}-\mathrm{C}_{\mathrm{T} \text { Sample HKG }} \\
& \Delta \mathrm{C}_{\mathrm{T} \text { Control Sample }}=\mathrm{C}_{\mathrm{T} \text { Control SampleHSP }}-\mathrm{C}_{\mathrm{T} \text { Control Sample HKG }} \\
& \Delta \Delta \mathrm{C}_{\mathrm{T}}=\Delta \mathrm{C}_{\mathrm{T} \text { Sample }}-\Delta \mathrm{C}_{\mathrm{T} \text { Control Sample }} \\
& \mathrm{RQ}=2^{-\Delta \Delta \mathrm{CT}}
\end{aligned}
$$

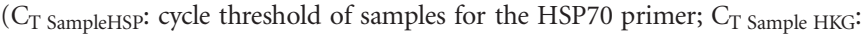
cycle threshold of samples for the housekeeping gene primer, Actin A1; $\mathrm{C}_{\mathrm{T}}$ Control SampleHSP: cycle threshold of control (outbred and $27^{\circ} \mathrm{C}$ ) samples for 
Table 2 Analysis of variance for the effects of inbreeding level (inbreed.), temperature treatment (temp.) and sex on HSP70 expression in the butterfly Bicyclus anynana

\begin{tabular}{lcccc}
\hline & MS & DF & $F$ & P-value \\
\hline Inbreeding level & $2.85 \times 10^{11}$ & 2 & 5.71 & $\mathbf{0 . 0 0 4 2}$ \\
Temperature & $2.72 \times 10^{11}$ & 2 & 6.30 & $\mathbf{0 . 0 0 2 5}$ \\
Sex & $9.32 \times 10^{10}$ & 1 & 2.16 & 0.1444 \\
Inbreed. $\times$ temp. & $2.32 \times 10^{11}$ & 4 & 5.38 & $\mathbf{0 . 0 0 0 5}$ \\
Inbreed. $\times$ sex & $8.38 \times 10^{10}$ & 2 & 1.94 & 0.1481 \\
Temp. $\times$ sex & $9.03 \times 10^{11}$ & 2 & 2.09 & 0.1280 \\
Inbreed. $\times$ temp. $\times$ sex & $7.99 \times 10^{10}$ & 4 & 1.85 & 0.1232 \\
Error & $4.32 \times 10^{10}$ & 130 & & \\
& & & &
\end{tabular}

Significant $P$-values are given in bold.

the HSP70 primer; $\mathrm{C}_{\mathrm{T}}$ Control Sample HKG: cycle threshold of control samples for the housekeeping gene primer).

Per plate we measured samples from all treatment groups simultaneously, though for males and females separately. To calculate $\Delta C_{\mathrm{T}}$ Control Sample, the respective control samples (outbred individuals kept at $27^{\circ} \mathrm{C}$ ) per plate were used. For subsequent statistical analyses we calculated the mean RQ value per individual, based on both replicate samples. Resulting expression data were analysed using a three-way analysis of variance with inbreeding level, temperature treatment and sex as fixed factors.

\section{RESULTS}

HSP70 expression was significantly affected by inbreeding level and temperature treatment (Table 2). Outbred controls tended to show a higher HSP70 expression than inbreeding levels 2 and 1 (C: $97669 \pm 60670=\mathrm{I} 2: 3299 \pm 2411=\mathrm{I} 1: 396 \pm 178$; Tukey HSD after analysis of variance), and heat-exposed individuals a higher one than cold-exposed and control individuals $\left(39^{\circ} \mathrm{C}\right.$ : $99210 \pm 59297=1{ }^{\circ} \mathrm{C}$ : $202 \pm 132=27^{\circ} \mathrm{C}: 28 \pm 14$; Tukey HSD after analysis of variance). Most strikingly though the upregulation of HSP70 at $39^{\circ} \mathrm{C}$ was much higher in control compared with inbred individuals (significant inbreeding level by temperature regime interaction, Figure 1).

\section{DISCUSSION}

The most striking result of our study is that inbreeding clearly interfered with HSP70 expression in B. anynana: animals from both inbreeding levels showed a minimal upregulation of HSP70 after heat exposure only, being reduced to $\sim 2 \%$ (I1: 0.4\%; I2 3.4\%) compared with outbred individuals. Inbreeding is well known to negatively affect fitness-related traits, including body mass, fecundity, fat content, survival and stress tolerance (for example, Franke and Fischer, 2013). Several lines of evidence suggest that such detrimental effects may be especially pronounced when individuals are exposed to stressful environmental conditions including heat (Armbruster and Reed, 2005; Fox and Reed, 2011). In Drosophila, for instance, inbred individuals may express conditional lethality under heat stress (Vermeulen and Bijlsma, 2004).

However, we are only beginning to understand which mechanisms and pathways may underlie the reduced fitness of inbred individuals (Calleri et al., 2006). Recent studies showed that several pathways may be upregulated in inbred as compared with outbred Drosophila individuals, whereas others, though less commonly occurring, are downregulated (Kristensen et al., 2005, 2006; Pedersen et al., 2005; García et al., 2012). Similarly, Ayroles et al. (2009) showed that inbreeding depression results in an overexpression of many genes associated with metabolism, stress or defence mechanisms.

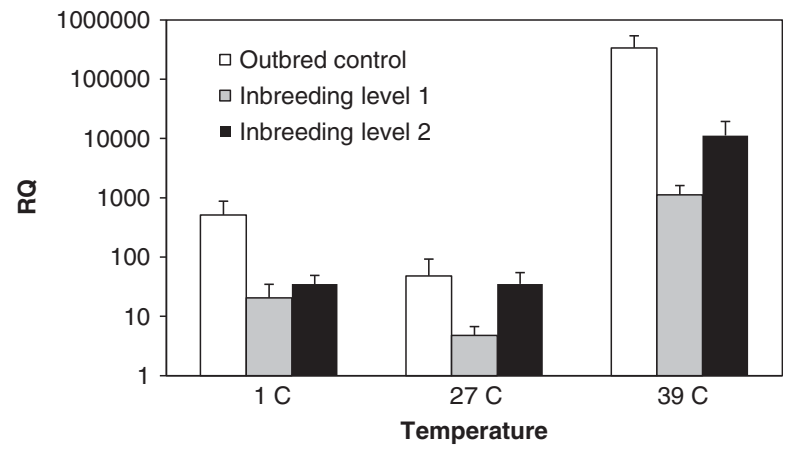

Figure 1 Expression of heat-shock protein (HSP) 70 in the butterfly Bicyclus anynana measured as relative quantification ( $R Q$; means \pm s.e.) in relation to inbreeding and temperature. Note the logarithmic scale.

Interestingly, some studies have documented increased HSP70 expression following inbreeding, which has been interpreted as part of a more general stress response which may include even 'genetic stress' caused by inbreeding (Kristensen et al., 2002; Cheng et al., 2006; but Bahrndorff et al., 2010). However, a higher HSP70 expression in inbred compared with outbred Drosophila larvae were only found at less stressful intermediate temperatures, whereas they disappeared under more stressful conditions (Kristensen et al., 2002; Cheng et al., 2006). The strikingly different pattern found in our study may thus suggest that, under low levels of environmental stress, inbreeding may cause increased HSP expression, whereas the response system may collapse completely in inbred individuals under high levels of stress. Note in this context that the high temperature used in our study was certainly very stressful for B. anynana. In addition, divergent inbreeding levels used may have contributed to the differences among studies.

Our study suggests that interference with the heat-shock response may be one mechanism underlying reduced fitness and increased mortality in stressful environments found in inbred individuals, at least in our study organism. Studies on B. anynana revealed increased mortality after heat exposure and reduced cold stress resistance in inbred compared with outbred individuals (Dierks et al., 2012; Franke and Fischer, 2013). Note that the heat-shock response is of wideranging importance for individual fitness as it generally supports protein function under stressful conditions (Kristensen et al., 2003; Ju et al., 2011). HSPs support the correct refolding of proteins and the alignment of newly synthesized proteins, and are upregulated by various stressors such as heat, UV radiation, ethanol or parasitism (Sørensen et al., 2003).

As expected HSP expression was strongly upregulated in (outbred) individuals exposed to heat in our study (Sørensen et al., 2009), which typically helps to maintain vital functions under heat stress. Several studies have found a positive correlation between heat tolerance and HSP70 expression (Bahrndorff et al., 2009), whereas others have shown opposite or no correlations (Dahlgaard et al., 1998; Bahrndorff et al., 2009, 2010). Using the same treatments as herein a previous study on B. anynana, we showed that exposure for $2 \mathrm{~h}$ to $39^{\circ} \mathrm{C}$ strongly increased subsequent heat-stress survival (Franke and Fischer, 2013), suggesting that a positive relationship between HSP70 expression and heat tolerance exists also in our study organism. Thus, an upregulation of HSPs may underlie the positive association between pre-exposure to heat stress ('hardening') and the increased subsequent heat tolerance (cf. Ju et al., 2011).

In addition to heat, HSP expression may also increase after exposure to cold, though responses are typically relatively weak 
(Feder and Hofmann, 1999; Karl et al., 2009). We here could not find an upregulation of HSP70 after exposure to $1{ }^{\circ} \mathrm{C}$. This could be due to the fact that either (1) the temperature $\left(1{ }^{\circ} \mathrm{C}\right)$ and/or the exposure time used $(2 \mathrm{~h})$ were not severe enough to elicit an emergency response, that (2) mechanisms other than the heat-shock response underscore plastic responses in cold tolerance in this species (cf. Colinet et al., 2010) or (3) methodological issues. Regarding the latter it should be noted that the upregulation of HSPs after cold exposure typically occurs at the end of the stress period or during recovery (Colinet et al., 2010). As in our study individuals were cold-stressed for $2 \mathrm{~h}$ only and afterwards frozen without a recovery time, the experimental design used may perhaps best explain the lack of effect.

Our study shows pronounced differences in HSP expression among temperature treatments and inbreeding levels in a tropical butterfly. Specifically, we show that pre-exposure to heat increased both HSP expression and heat-survival rate, and that inbred individuals expressed much less HSP under severe heat stress and were also less heat-tolerant than outbred ones (cf. Franke and Fischer, 2013). Most strikingly, we showed, using relatively mild and ecologically realistic levels of inbreeding, a strongly pronounced interference between inbreeding and the heat-shock response in our study organism: inbred individuals showed no upregulation of HSPs after heat stress. However, as our stock population has been kept under laboratory conditions for a long time, inbreeding, drift or laboratory adaptation may have changed the genetic constitution. Anyway, as the heat-shock response is of crucial importance for maintaining vital functions under heat and other stressors, we suggest that negative impacts of inbreeding on the heat-shock response may comprise an important mechanism underlying inbreeding depression such as increased mortality under stress in B. anynana. Clearly though more empirical data is needed exploring this relationship in an array of taxa before more general conclusions can be drawn. Such studies should use a broader range of temperatures and inbreeding levels, and should explore the effects of inbreeding in different important pathways.

\section{DATA ARCHIVING}

DNA sequences: GenBank Accessions FJ386397.1; NCBI. All other data are available from the Dryad Digital Repository doi:10.5061/ dryad.mh742.

\section{CONFLICT OF INTEREST}

The authors declare no conflict of interest.

\section{ACKNOWLEDGEMENTS}

We thank C Park and M Piesk for help during animal rearing, V Herkules for help during laboratory measurements, Dr C Wolke for introducing us into qPCR measurements and Dr M Haase and Professor Dr Gerald Kerth for providing access to their equipment. We are indebted to two anonymous reviewers for providing constructive criticism. This work was supported by the University of Greifswald and the Landesgraduiertenförderung of Mecklenburg Western Pomerania.

Armbruster P, Reed DH (2005). Inbreeding depression in benign and stressful environments. Heredity 95: 235-242.

Ayroles JF, Hughes KA, Rowe KC, Reedy MM, Rodriguez-Zas SL, Drnevich JM et al. (2009). A genomic assessment of inbreeding depression: gene number, function, and mode of action. Conserv Biol 23: 920-930.

Atkinson D (2008). Ectotherm life-history responses to developmental temperature. In: Johnston IA, Bennett AF (eds) Animals and Temperature: Phenotypic and Evolutionary Adaptation. Cambridge University Press: Cambridge, UK, pp 183-204.
Bahrndorff S, Mariën J, Loeschcke V, Ellers J (2009). Dynamics of heat-induced thermal stress resistance and $\mathrm{Hsp} 70$ expression in the springtail, Orchesella cincta. Funct Ecol 23: 233-239.

Bahrndorff S, Mariën J, Loeschcke V, Ellers J (2010). Genetic variation in heat resistance and $\mathrm{Hsp70}$ expression in inbred isofemale lines of the springtail, Orchesella cincta. Clim Res 43: 41-47.

Bechsgaard JS, Hoffmann AA, Sgró C, Loeschcke V, Bilde T, Kristensen TN (2013). A comparison of inbreeding depression in tropical and widespread Drosophila species. PLOS ONE 8: e51176.

Brakefield PM, Kesbeke F (1997). Genotype-environment interactions for insect growth in constant and fluctuating temperature regimes. Proc Biol Sci 264: 717-723.

Calleri DV 2nd, McGrail Reid E, Rosengaus RB, Vargo EL, Traniello JF (2006). Inbreeding and disease resistance in a social insect: effects of heterozygosity on immune competence in the termite Zootermopsis angusticollis. Proc Biol Sci 273: 2633-2640.

Cheng P, Liu X, Zhang G, Deng Y (2006). Heat-shock protein70 gene expression in four hatchery Pacific Abalone Haliotis discus hannai Ino populations using for markerassisted selection. Aquac Res 37: 1290-1296.

Colinet H, Lee SF, Hoffmann A (2010). Temporal expression of heat shock genes during cold stress and recovery from chill coma in adult Drosophila melanogaster. FEBS $J$ 277: $174-185$.

Dahlgaard J, Loeschcke V, Michalak P, Justesen J (1998). Induced thermotolerance and associated expression of the heat-shock protein Hsp70 in adult Drosophila melanogaster. Funct Ecol 12: 786-793.

David RJ, Gibert P, Pla E, Petavy G, Karan D, Moreteau B (1998). Cold stress tolerance in Drosophila: analysis of chill coma recovery of D. melanogaster. J Therm Biol 23: 291-299.

Dierks A, Hoffmann B, Bauerfeind SS, Fischer K (2012). Effects of inbreeding on life history and thermal performance in the tropical butterfly Bicyclus anynana. Popul Ecol 54: 83-90.

Feder ME, Hofmann GE (1999). Heat-shock proteins, molecular chaperones, and the stress response: evolutionary and ecological physiology. Annu Rev Physiol 61: 243-282.

Fischer K, Dierks A, Franke K, Geister TL, Liszka M, Winter S et al. (2010). Environmental effects on temperature stress resistance in the tropical butterfly Bicyclus anynana. PLOS ONE 5: e15284.

Fox CW, Reed DH (2011). Inbreeding depression increases with environmental stress: an experimental study and meta-analysis. Evolution 65: 246-258.

Franke K, Fischer K (2013). Effects of inbreeding and temperature stress on life history and immune function in a butterfly. J Evol Biol 26: 517-528.

García C, Ávila V, Quesada H, Caballero A (2012). Gene-expression changes caused by inbreeding protect against inbreeding depression in Drosophila. Genetics 192: 161-172.

Hoffmann AA, Hercus MJ (2000). Environmental stress as an evolutionary force. Bioscience 50: 217-226.

Huggett J, Dheda K, Bustin S, Zumla A (2005). Real-time RT-PCR normalization; strategies and considerations. Genes Immun 6: 279-284.

Ju RT, Chen GB, Wang F, Li B (2011). Effects of heat shock, heat exposure pattern, and heat hardening on survival of the sycamore lace bug, Corythucha ciliata. Entomol Exp App/ 141: 168-177.

Karl I, Sørensen JG, Loeschcke V, Fischer K (2009). HSP70 expression in the Copper butterfly Lycaena tityrus across altitudes and temperatures. J Evol Biol 22: 172-178.

Koštál V, Tollarová-Borovanská M (2009). The 70 kDa heat shock protein assists during the repair of chilling injury in the insect, Pyrrhocoris apterus. PLOS ONE 4: e4546.

Kristensen TN, Dahlgaard J, Loeschcke V (2002). Inbreeding affects Hsp 70 expression in two species of Drosophila even at benign temperatures. Evol Ecol Res 4: 1209-1216.

Kristensen TN, Sørensen JG, Loeschcke V (2003). Mild heat stress at a young age in Drosophila melanogaster leads to increased Hsp70 synthesis after stress exposure later in life. J Genet 82: 89-94.

Kristensen TN, Sørensen P, Kruhøffer M, Pedersen KS, Loeschcke V (2005). Genome-wide analysis of inbreeding effects on gene expression in Drosophila melanogaster. Genetics 171: 157-167.

Kristensen TN, Sørensen P, Pedersen KS, Kruhøffer M, Loeschcke V (2006). Inbreeding by environmental interaction affect gene expression in Drosophila melanogaster. Genetics 173: $1329-1336$.

Larsen TB (1991). The Butterflies of Kenya. Oxford University Press: Oxford, UK.

Lindquist L (1986). The heat-shock response. Annu Rev Biochem 55: 1151-1191.

Livak KJ, Schmittgen TD (2001). Analysis of relative gene expression data using real-time quantitative PCR and the $2^{-\Delta \Delta C}$ Tethod. Methods 25: 402-408.

Lyytinen A, Brakefield PM, Lindstrom L, Mappes J (2004). Does predation maintain eyespot plasticity in Bicyclus anynana? Proc Biol Sci 271: 279-283.

Mikkelsen K, Loeschcke V, Kristensen TN (2010). Trait specific consequences of fast and low inbreeding: lessons from captive populations of Drosophila melanogaster. Conserv Genet 11: 479-488.

Pedersen KS, Kristensen TN, Loeschcke V (2005). Effects of inbreeding and rate of inbreeding in Drosophila melanogaster - HSP 70 expression and fitness. J Evol Biol 18: 756-762.

Sørensen JG, Kristensen TN, Loeschcke V (2003). The evolutionary and ecological role of heat shock proteins. Ecol Lett 6: 1025-1037.

Sørensen JG, Vermeulen CJ, Flik G, Loeschcke V (2009). Stress specific correlated responses in fat content, Hsp70 and dopamine levels in Drosophila melanogaster selected for resistance to environmental stress. J Insect Physiol 55: 700-706. 
Teng X, Zhang Z, He G, Yang L, Li F (2012). Validation of reference genes for quantitative expression analysis by real-time RT-PCR in four lepidopteran insects. J Insect Sci 12 1536-2442.

Ullmannová V, Haškovec C (2003). The use of housekeeping genes (HKG) as an internal control for the detection of gene expression by quantitative real-time RT-PCR. Folia Biol (Praha) 49: 211-216.
Van't Hof AE, Zwaan BJ, Saccheri IJ, Daly D, Bot ANM, Brakefield PM (2005). Characterization of 28 microsatellite loci for the butterfly Bicyclus anynana. Mol Ecol Resour 5: 169-172.

Vermeulen CJ, Bijlsma R (2004). Characterization of conditionally expressed mutants affecting age specific survival in inbred lines of Drosophila melanogaster lethal conditions and temperature-sensitive periods. Genetics 167: 1241-1248. 